\title{
Innovations in contemporary marketing through artificial intelligence and robotic drones
}

\author{
A. Pamnani ${ }^{1^{*}}$ and V. Parvathi ${ }^{2}$ \\ ${ }^{1 \& 2}$ GITAM Hyderabad Business School, Hyderabad, India
}

DOI: http://doi.org/10.52814/PJMA.2021.1105

ARTICLE TYPE: Review paper

ARTICLE HISTORY: Submitted: January 2021, Revisions: March 2021, Accepted:

March 2021

HOW TO CITE: Pamnani, A. and Parvathi, V. (2021). Innovations in contemporary marketing through artificial intelligence and robotic drones. Prayukti - Journal of Management Applications, Vol. 1, Issue 1, pp. 34-43.

*Corresponding author e-mail: avishkar.pamnani1@gmail.com

\begin{abstract}
The marketing industry has undergone rapid changes since the dawn of the new millennium. Technology has become an integral part of contemporary brand marketing techniques. It is a tool which helps bring brands to life and also evaluate how consumers interact and see brands. This research paper analyses the role of 'Artificial Intelligence' and 'Robotic Drones' in helping create and manage, innovative marketing campaigns for companies and Government organisations. Cloud Computing, Natural language processing, Data Analytics and other Internet related technologies are evolving day by day. They will be used for performing cross functional hand shake with high tech drones, which will eventually have a huge impact on the field on marketing. Artificial Intelligence will form the back bone of this new genre. Drone technology being used for marketing is giving birth to new methods of marketing, which haven't been seen in the past before. By using drones to accumulate and eventually integrate the available data, new marketing campaigns can be designed which will lead to more innovative techniques. SWOT analysis of Innovative Creative Marketing through 'Artificial Intelligence' and 'Drones' has been covered in this research paper and critical evaluation analysis has been done of each stage. Brand management is key towards a successful marketing campaign. As artificial intelligence and drone technology, start entering this domain it will need to new and creative ways of gathering data, which will help in launching innovative marketing campaigns. Engaging the customers will be done at a whole new level. The evolution of drones for commercial marketing has evolved quite recently in the past few years. Yet, it has highlighted an immense potential for the next frontier of marketing. This research paper, concludes by giving us suggestions on how the future in this field is going to be and the amalgamation of new and niche technologies like these, is going to change the world of Marketing forever in the decades to come.
\end{abstract}

KEYWORDS: Innovations, Robotic Drones, Big Data, Contemporary Marketing, AI 


\section{INTRODUCTION}

Innovation marketing comprises of marketing activities in the innovation process. Research is done into the requirements of a customer's needs and requirements. Testing prototypes with a small set of users initially and then moving towards a larger group, is the key towards a successful Innovation based marketing campaign. Success of innovation depends on a large part upon the role of innovation marketing. The primary goal of the field of marketing, is to help increase sales. Customer's needs, need to be aligned with the services and processes for all products and the primary focus remains on market orientation. Market research and strategic key tasks help us in identifying the current needs of the customer and also in preparing for the future needs. It also helps us in exploring possible market potentials. ${ }^{1}$ Corporate strategy helps in preparing marketing plans. Development of strategies also revolves around marketing. There are four key elements which are integral to it -- Design of the Product, Cost and Price policy, communication media and sales distribution channels. Often, we come across certain overlaps happening between marketing and innovation management. The function of innovation management also includes analyses of trends, which help in defining policies used for development of products and their design. Innovation marketing helps in contributing towards the designing of a successful product. Continuously involving customers at each stage, is the key factor that helps us in achieving the task of collecting inputs and feedbacks from customers on current business developments. Feedback is obtained with the help of prototype testing and beta version tests. Future acceptance of products and including experiences helps in the development of key tasks and processes. In internal marketing, the company's own in-house teams and staff will need to be convinced of the new product innovations, as that's the only key way to bring new products into the market. External marketing involves all key parts of the marketing cycle, from pricing, costing, advertising, channels for sales and other sub-ordinate functions. Cross functional tasks in Innovation marketing involve all three stages from front end to back end and development in between. Tasks related to marketing and innovation are often intertwined and inter woven hand in hand ${ }^{2}$.

\section{IMPORTANCE OF INNOVATION MARKETING}

Innovation marketing is integral to all stages of a marketing cycle and one of its main goals is to ensure that customer orientation and market enablers, play an important role in avoiding failure at the innovation stage. In case if priority is not given to innovation marketing, it can also lead to many risks and inherent dangers. Companies end up making wrong decisions if there is lack of adequate data about the target consumer market and also the product, which can lead projects in incorrect directions and finally collapse. Certain times, we might observe that a commodity is not doing well in the market. This does not mean that it is not up to the mark. Some below average and mediocre products also do well in markets and are often quite successful. Marketing is hence important in contributing towards the internal as well as external success of a product. Product success is based on multiple factors, but the main factor is by using an effective Marketing campaign.

\section{ARTIFICIAL INTELLIGENCE (AI) MARKETING}

Artificial Intelligence based technologies help us to make decisions which are based on analysis, collection and interpretation of data. It is primarily used in the marketing tasks, where time is limited and speed is the foremost essential parameter. The tools used for Artificial Intelligence use raw data, which helps them in identifying how best they can communicate with the users and the customers, which will help them in designing and customising tailored product requirements at the appropriate time without manual

\footnotetext{
1 Marketing Innovation | Definition of What is Marketing Innovation by IGI Global Publishers. (2021). Retrieved from https://www.igi-global.com/dictionary/innovation-scope-and-the-performance-of-thefirm/44798.

2 Importance of Innovation Marketing | LEAD Innovation Blog. (2019). Retrieved from https://www.leadinnovation.com/english-blog/innovation-marketing.
} 
intervention of multiple people, thus improving the efficiency and ensuring maximum desired output. In today's contemporary times, Artificial Intelligence ${ }^{3}$ is used by multiple subsets of marketing teams with minimal human support.

\section{Some of the key components of Artificial Intelligence marketing includes}

- Personalization of data in real-time

- Analysis of Data

- Decision Making automation

- Generating content automatically

- NLP (Natural Language Processing)

- Big Data and Analytics

Digital media has made rapid strides in the past few decades and this has brought in a large amount of data, referred to as 'Big Data'. This helps provide numerous opportunities for marketing companies and sales channels distributors to pin point and accurately target their customer base spread across various domains and channels. Sometimes, it might lead to saturation of data as well, since marketing companies are sometimes unable to determine what sort of data needs to be collected and which data to ignore or discard.

\section{Machine Learning:}

It is a subset of Artificial Intelligence. A machine can learn and thus quickly analyse and automate models for handling large data, which is complex in nature. Faster delivery and turnaround time, with higher level of accuracy on large scale is the key towards making machine language a key tool in the field of marketing. These mathematically oriented precision model tools, help an organization in identifying more profitable venues and avoid risks, which can cause failures.

Fig. 1 : Big Data \& Analytics

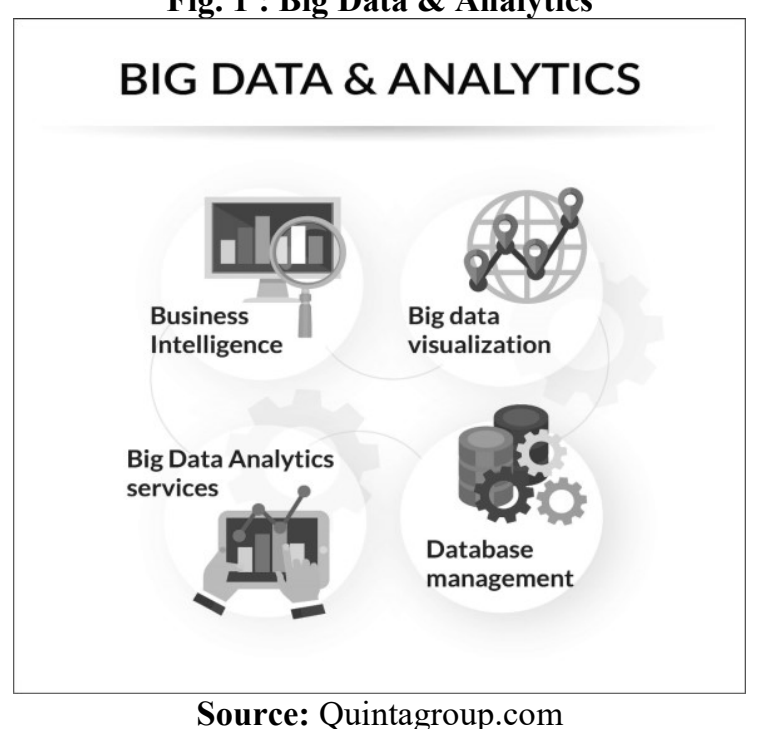

\section{Managing and Organising Marketing Data:}

In order to design marketing strategies, we need data which has to be of high quality and organized well, so that it can be analysed reliably. Data often flows in and out of organisations on a regular basis and that is why it is essential to setup processes which are repeatable in nature 4 . When these protocols have been put in place, then we can automate and create master programs for managing the data.

\footnotetext{
${ }^{3}$ What is Artificial Intelligence (AI) Marketing | Marketing Evolution. Forum (2021). Retrieved from https://www.marketingevolution.com/marketing-essentials/ai-marketing

${ }^{4}$ Big Data Analytics. What it is and why it matters | SAS Insights (2021).
} 


\section{Data Mining:}

Large amounts of data need to be broken down in a systematic manner and we have to look for patterns within the data in order to make sure that the available information is good enough to be used for further review. This will help in answering complex questions related to key business decision making processes. There are numerous data mining software and related technologies available in the market, which can help us in sifting through vast and repetitive data and help us in pinpointing accurately and improve the speed of decision making.

\section{Hadoop:}

The primary advantage of using Hadoop is that it is an open-source framework for storing data which is complex and large in number. Clusters can be used for storing and running large amounts of data on common hardware platforms. Due to constant flow of large amounts of data and the varieties of types of data, this plays a key role in helping businesses run efficiently. As Hadoop is free, it is more widely used, when large amounts of data are used.

\section{Predictive Analytics:}

Statistics and machine learning based algorithms, help us to recognise what will be the future outcome of certain functions 5 based on the past available historical data. As the word 'Predictive' suggests, it helps us in giving a best-case scenario assessment. Primarily in the field of marketing, it is used for detecting frauds, risk mitigation and operations related marketing tasks.

\section{Text Mining:}

This is another key aspect of marketing, where we can analyse the text of the data from the Internet and other online sources. The key element here is to analyse the insights of items which haven't been noticed on earlier occasions. Machine learning and natural language processing is used for analysing emails, web fees and thus generate strategic intelligence.

Fig 2 : Machine Learning

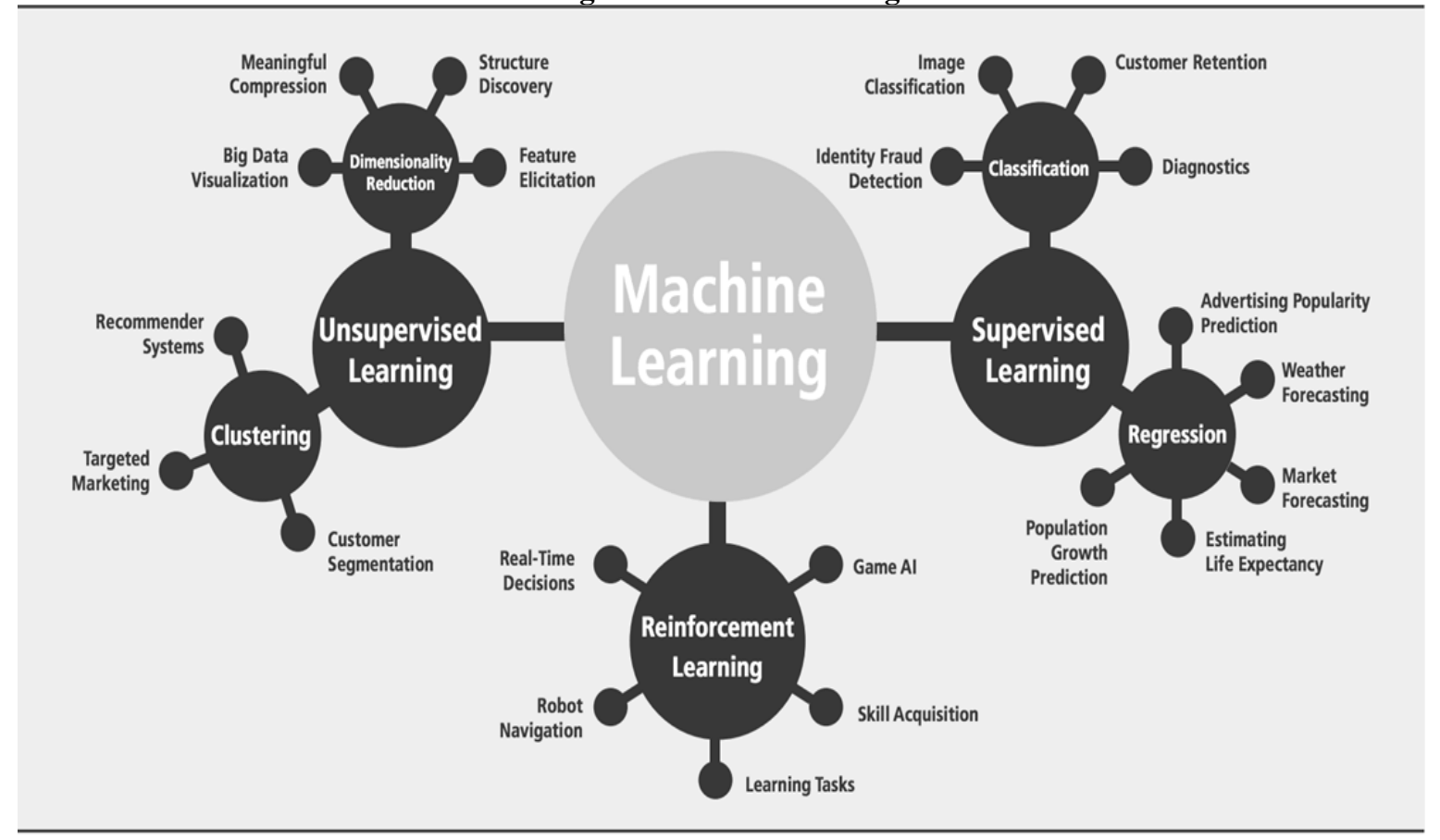

Source: tech savvy word press

Retrieved from https:/www.sas.com/en_in/insights/analytics/big-data-analytics.html

${ }^{5}$ What are Predictive Analytics | Predictive Analytics (2020).

Retrieved from https://www.predictiveanalyticstoday.com/what-is-predictive-analytics/ 


\section{CHALLENGES FOR ARTIFICIAL INTELLIGENCE MARKETING}

Contemporary marketing depends on a deep-rooted understanding of the various needs of customers and their preferences. This also includes the ability to act on that information and deliver on it effectively and in a timely manner. Artificial Intelligence has brought the ability to make decisions which are data driven on a real time basis, to the forefront of the various marketing companies. Development Artificial Intelligence based tools for marketing is still in its nascent stage and hence, the challenges are numerous.

\section{QUALITY OF DATA AND TIME TAKEN FOR TRAINING}

Artificial Intelligence based tools are not automatically programmed to know which key actions are needed to be taken in order to help marketing firms achieve their goals. These tools need time and automation-based training in order to learn and understand the key customer requirements and preferences, analyses of historical data trends and establish expertise overall. We also need to factor in the quality of data for assurance purpose 6 . When we fail to adequately train the Artificial Intelligence based tools, we cannot expect to get high quality data or accurate data in a timely manner. These tools will eventually make decisions which are not optimal in nature and thus do not reflect the customers right desires, hence removing the value of the Artificial Intelligence based tool.

\section{MARKETING DATA PRIVACY}

Government regulators and organisations are often faced with problems related to privacy of an individual's data. Various marketing organizations often have to face serious challenges related to using customer data in an ethical and coherent manner. Complying with key standards, are essential to ensuring privacy of data and thus avoid damaging reputations of well-established firms ${ }^{7}$. The Artificial Intelligence based tools have to be programmed in such a manner that they follow the ethical and legally defined guidelines, otherwise crossing these red lines would lead to unacceptable damage in leakage of personalized data of consumers.

\section{RETURN ON INVESTMENT (ROI)}

Stakeholders often have to be convinced about the viability of investment in the development of Artificial Intelligence based tools. Key performance indicators are not always quantifiable. Return on Investment and efficiency in performing tasks are not always measurable in terms of numbers. There is no such way of predicting how we can use Artificial Intelligence for improving customer experience. Even improving a brand's reputation is not always measurable in terms of numerical data. Thus, marketing companies always need to make sure that they can measure these factors numerically, otherwise they cannot dedicate and attribute these improvements and gains towards Artificial Intelligence based tools.

\section{INTRODUCTION TO DRONES}

Technology has been evolving every day and there is a new tool which has evolved in improving marketing campaigns of various industries. Drones are being actively used and their potential is slowly being understood. Various organizations are using drones for publicising about their products. The foot age gathered from drones helps in improving the strategies used by various companies for their marketing campaigns. In the layman's terms, drones are actually unmanned aerial vehicles which are often described as 'Robots that can Fly'. They can be operated remotely with the help of on-board computers and hardware data links inter connected to related equipment. Some drones have loitered time of around an hour

\footnotetext{
${ }^{6}$ Commercial Drones Are Revolutionizing Business Operations | Finance Processes (2020). Retrieved from https://www.toptal.com/finance/market-research-analysts/drone-market

${ }^{7}$ Data Privacy Rules Are Changing. How Can Marketers Keep Up? | Data Privacy Rules (2020). Retrieved from https://hbr.org/2020/08/data-privacy-rules-are-changing-how-can-marketers-keep-up
} 
as well ${ }^{8}$. The video footage gathered by drones is usually of high resolution and clarity. This helps in making a huge impact, as the drones provide view of the surroundings which cannot be easily gathered or visible from the ground levels. Marketing teams can use this for their video campaigns and improve visibility amongst their customers. Before marketing teams start using drones, they have to realise that there are legal aspects related to flying drones. Businesses and organisations have to obtain three important approvals before they start using drones for their use. Certified registered aircrafts, licensed pilots and government approvals.

Fig 3: Ethical Challenges of Artificial Intelligence

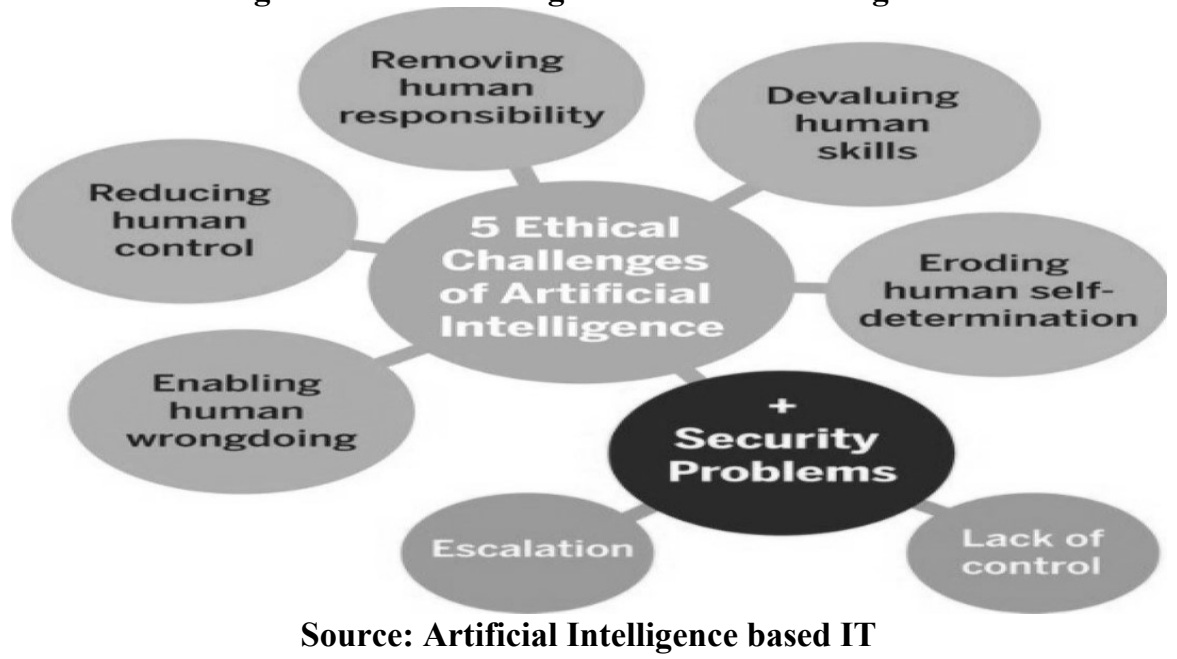

\section{USING DRONES FOR MARKETING CAMPAIGNS}

Drones are often used for either complementing or spearheading marketing campaigns which are based completely around them. When the videos are taken from the ground level, they may not give a holistic view of the whole surroundings. But, shooting videos from the sky with the help of drones, gives very clear and clean footage that is more impactful. When these are used for marketing campaigns, the websites, advertisements, materials used for printing, all leave a huge impression on the target audience. Drone marketing can be incorporated and add value to existing strategies which are used for marketing:

1. Print Media

2. Social Media

3. TV Advertisements

4. Blogs on the Internet

5. Digital ads

6. Electronic News and newsletters

\section{DRONE USES IN MARKETING CAMPAIGNS}

1. Yearly Reports of Companies Internet Sites

2. YouTube Videos

3. Social Media tools

4. Brochures

5. Flyers

6. Displays during Trade Shows

7. Bill boards

8. Park Benches

9. Advertising Outdoors

10. Branding through normal channels

\footnotetext{
${ }^{8}$ How Drones Can Elevate Your Traditional \& Digital Marketing Campaigns | APPLETON (2021). Retrieved from https://www.appletoncreative.com/blog/how-drones-can-elevate-your-traditional-digital-marketingcampaigns/
} 
Often organisations employ the services of agencies which are not just well versed in marketing through video campaigns, but also those who specialize in incorporating drones and their footage on their websites. Digital campaigns also include footage of properties and buildings that have been shot using drones. Various social media channels can be used for marketing these more affectively. Facebook, Instagram, Twitter, YouTube, often use these video-based footages which have been taken with the help of drones. This helps in improving the daily viewer visits to these sites and promotion of these auto played videos leads to more creative and wide spread publicity, which not only captures attention, but also helps in turning the followers of these videos into successful customers permanently.

\section{INDUSTRIES WHICH USE DRONES FOR THEIR MARKETING CAMPAIGNS}

Drones have utility across different domains. Building construction, land development, movie industry, films, movie houses, news channels are some of them. The depth and expanse of products which were earlier restricted to a handful of consumers, expanded rapidly through the commercial use of drones. The best example that we can site is of the real estate industrial sector. Drone photography is used for capturing videos of real estate ventures ${ }^{9}$. Helicopters were earlier used for capturing the aerial views of buildings and other ventures which were used by property dealers. But, after the advent of drones these have become more cost affordable and their accessibility has also increased much more than before. This also helps them in marketing multiple properties at the same time, in a more time efficient manner. Traffic patterns can also be analysed using drones, thereby marketing properties and ventures more affectively in commercial locations. While real estate is just one of the industries that has used drones affectively for marketing campaigns, there are many more industries which have hopped onto the drone marketing band wagons.

Fig 4: Survey on the industrial use of drones

Survey on the industrial use of drones

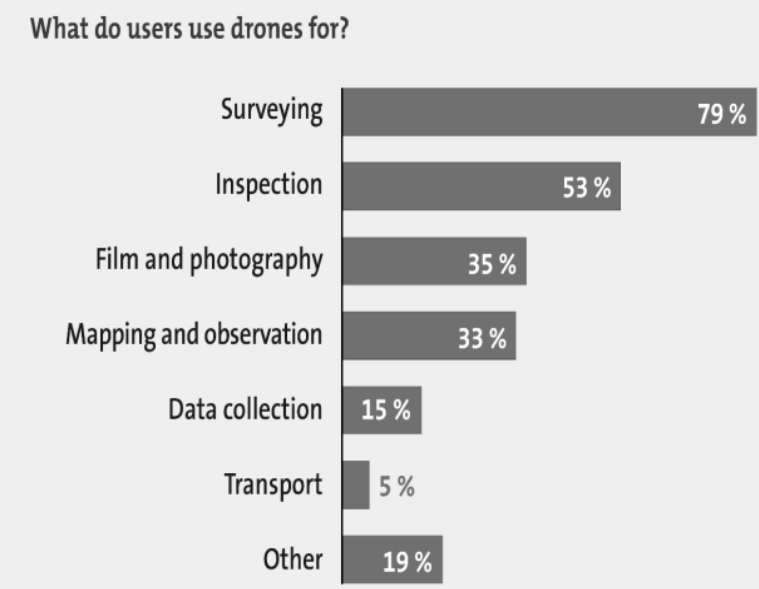

Multiple answers possible

Source: VUL Analysis of the German Drone Market October 2018

www.bdl.aero

\section{Source: bbl.aero}

\section{WAY FORWARD FOR MARKETERS}

\subsection{Drone as a tool for Marketing:}

The best way that we can visualize a drone keeping marketing in mind, is to use it as a tool. The drone, realistically speaking will be used for recording various perspectives with the

\footnotetext{
${ }^{9}$ Commercial drones: industries that use drones, deliverables, and our list of the top models on the market | fly ability (2021). Retrieved from https://www.flyability.com/commercial-drones
} 
help of a camera, that in normal circumstances would require a lot of time and along with that quite a bit of money and effort. The associated costs that were used for cranes, helicopters, planes for shooting commercials, have now been dealt with and replaced by marketers with the help of use of drones. Breath taking air footage videos have become the best way for marketers to employ drones and utilize them to their fullest capacity.

\subsection{Artificial Intelligence based Quick Marketing:}

Drone Technology has seen rapid advancements, primarily due to their ease of use. Even amateurs have been taking good video footages with the help of drones, thus improving the chances of using drones for Quick Marketing. Sometimes, drones can also be controlled with the help of applications which we can deploy using our smart phones. Drones are also used for pushing quick marketing campaigns. Advertisers no longer have to be worried about the logistics being used for their marketing campaigns. Even red tape, which used to create bottle necks is no longer an impediment as all the tools needed for running a successful marketing campaign can be found in a single device. Professionals with experience of operating drones, can help in promoting a quick and efficient way of marketing.

\subsection{Drones being used as Actors:}

There is a popular misconception that drones can be used only for purposes of recording videos. But, the fact of the matter is that they can be used for doing much more than that ${ }^{10}$. Drones can actually be the main centre of attraction and act as focus points, during these marketing campaigns. Drones appear to be quite fascinating to some people, as they like to see them flying around, performing aerial displays which are very attractive to the human eyes and perception.

\subsection{Drones effectively being used as a Platform:}

The biggest advantage of using drones, is that they do not have any geographical confines or limitations. The age-old traditional methods of marketing primarily consisted of using print advertisements, commercials shown on $\mathrm{TV}$, ads on bill boards and some Internet based advertising. This is where drones get into the picture. Drones are providing new opportunities for advertising companies to take advantage of in a cost-effective manner. There are limitations of using platforms which are stationary in nature, such as bill boards and road signs. Drones can instead help us, by taking these campaigns to the door steps of people and do it in an aggressive way. A good example would be, in some restaurants and hotels the advertisements of menus are shown with the help of drones, instead of spending money on banners and posters which are displayed at large gatherings. Drone advertisements do not have this limitation and can legally be used as per local laws for affective marketing. This will help them in realising their potential to the maximum.

\subsection{Limitless potential for Creativity:}

Drone technology offers limitless potential for creative purposes. They can be programmed to analyse patterns and sync up accordingly. Marketing need not be practical or straight forward always. Drones can be a powerful tool which can leave an everlasting image on the audience. The impression thus created using drones, can also be used to build brand value with our audience and customer base. Drone technology is just in its nascent evolving stage and its poised to expand and evolve over the coming decades. It is advisable for media marketing managers to ensure that they are up to date with reference to the new and upcoming technological advances in the field of marketing. Novel ways of using drones is increasing by the day and people are figuring out more and more unique ways of utilising drones for their marketing campaigns. Staying ahead in the game is the cardinal rule of

\footnotetext{
${ }^{10}$ Five Ways Marketers Can Take Advantage Of Drone Technology | Forbes (2021). Retrieved from https://www.forbes.com/sites/ajagrawal/2017/06/10/5-ways-marketers-can-take-advantage-of-drone-technology/
} 
marketing and as more and more marketers, get into the space of using drones, the future offers us exciting new opportunities.

\section{USING DRONE DATA FOR SUPPORTING MARKETING CAMPAIGNS}

Drone data can help reduce redundant marketing campaign-based messages. They can be used for targeting people belonging to certain demographics. Often marketers need to modify campaigns and responses based on these demographic trends. Social gatherings and other events can help in collecting data with the help of drones and then marketers can accordingly use these channels of advertising in order to reach out to these sets of people with the help of relevant products and services. Location based drone data is also being used affectively in target-based campaigns now-a-days. In order to ensure that drone-based campaigns are successful, the content which has been created with the help of drones should be available across various social media platforms across the board. Using the footage from drones in a timely manner, can help in giving an effective and useful real time result, that benefits the consumers. Aerial view of the imagery acquired with the help of drone technology can give a faster and more accurate view of the product. This can be done through the use of improved quality and though provoking engagement of visual content through multiple sequence of events. New consumers unfamiliar with the variety of products available in the market, can get more accustomed to getting their views and opinions based on drone statistical data, instead of depending only on a single source of information and the pricing data model available in the market. The key factor in drone marketing is that you can get the ROI (Return on Investment) feedback in a timely manner and straight from the field. This can then be used to market the products through various channels in a cost-efficient manner. Thus, drones can be used adequately in supporting marketing campaigns all across the spectrum, right from the initial stage to the maturity stage.

\section{CONCLUSION}

Drone marketing has become an integral part of today's technology driven era. Drones have helped make marketing innovative and livelier. Marketing campaigns based on visual and video footage acquired from drones, is the new normal and multiple business houses are today joining this highway in order to create new and captivating marketing campaigns. Brand and Image building is being done with the help of drones. There are multiple sectors which have been employing drones.

Some of these include agriculture based, insurance monetary sectors, high technology and engineering, buildings real estate development, petroleum and natural. Even industries such as tourism and movie making have been adopting this drone technology on a large scale. In the near future, drone usage will be on a much wider scale and those not joining the drone band wagon will be left behind, in this modern technology-based marketing era. Creativity has no limits and as such the utility of drones being used by businesses is only limited by the creative thoughts of various marketing teams.

It is important for us to understand that drones will not be replace existing marketing methodologies all together. In order to utilise and use drones to their maximum capacity, it is important for us to understand their limitations as well. Drones are to be used to add value and strengthen the existing marketing practises used by marketers. Marketing teams are also using drones to achieve very thoughtful perspectives and views with the help of advertisements and videos for promotional use. Photo and video-based coverage has acquired wide acceptability and the collection of information and data, helps in report generation on a real time scale.

The bottom line to note is that drone technology will help us in facilitating the process of turning concepts into reality. It will help marketing teams take the next leap forward and transition from the rudimentary marketing campaigns to a more final product high technology driven campaign. We can come to a conclusion that no matter which industry, it makes a lot of business sense to use drones as a marketing tool. The future of drone marketing has truly arrived. 


\section{REFERENCES}

- Artificial intelligence | Definition of artificial intelligence in English by Oxford Dictionaries. (2019). Retrieved from https://en.oxforddictionaries.com/definition/artificial_intelligence.

- Dhar, V. (2016). The Future of Artificial Intelligence. Big Data, 4(1), 5-9, https://doi.org/10.1089/big.2016.29004.vda.

- Grawal, A., Gans, J. S., \& Goldfarb, A. (2017). What to Expect from Artificial Intelligence? MIT Sloan Management Review. Retrieved August, 10, 2018, from https://sloanreview.mit.edu/article/what-to-expect-from-artificial-intelligence/.

- Importance of Innovation Marketing | LEAD Innovation Blog. (2019). Retrieved from https://www.lead-innovation.com/english-blog/innovation-marketing.

- Jordan, M. I., \& Mitchell, T. M. (2015). Machine learning: Trends, perspectives, and prospects. Science, 349(6245), 255-260. https://doi.org/10.1126/science.aaa8415.

- Kumar, A.; Gawande, A. and Brar, V. (2020). Features of Marketing Resilience. Vidyabharati International Interdisciplinary Research Journal, Vol. 11, Issue 01, pp. 250-253.

- Kumar, Atul and Brar, Vinaydeep (2018). Digital Marketing and Role of Blockchain in Digital Marketing Industry. International Journal of All Research Education and Scientific Methods, Vol. 6, Issue 12, pp. 23-26.

- Lieto, A., Bhatt, M., Oltramari, A., \& Vernon, D. (2017). The role of cognitive architectures in general artificial intelligence. Cognitive Systems Research, 48, 1-3, https://doi.org/10.1016/j.cogsys.2017.08.003.

- Marketing Innovation | Definition of What is Marketing Innovation by IGI Global Publishers. (2021). Retrieved from https://www.igi-global.com/dictionary/innovationscope-and-the-performance-of-the-firm/44798.

- Mazurek, G. (2014). Network Value Creation through Marketing, Management \& Business Administration. Central Europe, 22(4), 70-77. https://doi.org/10.7206/mba.ce.2084-3356.120.

- McIlwraith D., Marmanis H., \& Babenko D. (2017). Inteligentna sieć. Algorytmy przyszłości. Helion, $2^{\text {nd }}$ edition, Gliwice, p. 27.

- Palmer, A. (2004). Introduction to Marketing - Theory and Practice. UK: Oxford University Press.

- Rukmathan, R. and Kavitha, V. (2019). A Study on Impact of Emotional Intelligence with Job Performance of Nurses in Coimbatore. MERC Global's International Journal of Management, Vol. 7, Issue 4, pp. 301-306.

- Shanahan, M. (2015). The Technology Singularity. MIT Press.

- What is Artificial Intelligence (AI) Marketing | Marketing Evolution Forum (2021). Retrieved from https://www.marketingevolution.com/marketing-essentials/aimarkeitng

- What is Marketing? - The Definition of Marketing - AMA. (2019). Retrieved from https://www.ama.org/the-definition-of-marketing/. 